\title{
Robust regulations
}

\author{
Recent threats to the Endangered Species Act in the USA and the battle to prevent logging in Poland's Białowieża \\ Forest highlight the need for robustness in environmental protection measures.
}

T he legal mechanisms for protecting biodiversity are varied and complex, but their robustness to political or commercial interference is what distinguishes the strong from the weak. The strength of two distinct but complementary mechanisms - that of protecting species and that of protecting areas - is currently being put to the test in both the USA and Europe.

The Endangered Species Act in the United States, enacted by President Richard Nixon, has offered protection to over 2,000 species on its endangered and threatened lists over the past 45 years. Perhaps its most important component is the designation of critical habitats for every listed species, which are protected from destruction and disturbance. The overall effectiveness of the Act has been debated, but the number of species removed from the list because they have recovered outnumbers those that have gone extinct, and iconic successes include the bald eagle and the grizzly bear.

A key part of making the Endangered Species Act robust is its explicit provision that economic considerations do not contribute to determining which species to list or habitats to designate. Without this provision, it would be much easier for commercial interests or politicians who are hostile to the Act to undermine its effectiveness when implementing it. It is therefore of great concern that, amongst various attempts by the Trump administration and some other Republican legislators to scale back the Act, there is a proposal from the Fish and Wildlife Service to remove the phrase "without reference to possible economic or other impacts of such determination". This proposal is currently under a 60-day public consultation, and does not require congressional approval, making it far more likely to be approved than some of the other proposed changes. Scientists and conservationists will fight these changes, and they should endeavour to enlist the support of the American public, who are overwhelmingly in favour of the Act according to a recent study ${ }^{1}$. Importantly, the support is bipartisan, with conservatives supporting it by only a slightly smaller margin than liberals.

Meanwhile, in Europe, a political and judicial battle has been raging over the conservation of Białowieża Forest. The forest, which straddles Poland and Belarus, is one of the largest remaining tracts of oldgrowth forest in Europe. It is no surprise that, in his book Half-Earth ${ }^{2}$, it is the only European site selected by E. O. Wilson as one of his 31 'best places in the biosphere'. On the Polish side of the border, only $17 \%$ of the forest is a designated national park, with a further $19 \%$ being nature reserves and the remainder being managed forest ${ }^{3}$. The Polish government has increased logging in the managed forest in recent years, in a stated effort to eradicate spruce bark beetle, which is damaging trees. However, ecologists have argued that the logging is economically motivated and will cause more harm than good, and that the beetle outbreak should be left to run its course $e^{4}$. This debate led to the European Commission taking the case to the EU's European Court of Justice, which ruled earlier this year that the logging had indeed been unlawful. Specifically, it contravened the Birds and Habitats directives, which are Europe's legislative counterpart to the Endangered Species Act in the United States.

Poland's Białowieża is a Natura 2000 site, part of the network of protected sites that arises from the Birds and Habitats directives. As the largest such network in the world, it is a powerful tool for the preservation of European biodiversity. But it is not perfect. Natura 2000 sites are not all strict nature reserves and many of them are privately owned land. In Białowieża, the argument over whether logging is supported by scientific evidence is not an impartial one because of the lack of strict protection in the managed forest. There is not necessarily a definitive strategy for dealing with bark beetle outbreaks, but the scientific discussion cannot be unbiased when there are potential competing interests that undermine the credibility of the arguments in favour of logging. For this reason, it has been argued that the Białowieża situation will only be properly resolved by expanding the strict national park to incorporate the entire forest, in which case the scientific arguments will be the only relevant ones in deciding how to deal with the bark beetles.

The Endangered Species Act and the Europa 2000 network are different approaches to designating land for protection, one based on individual species, and the other on habitat types. But they are both world-leading initiatives with great power. The threat of commercial considerations being included in the Endangered Species Act illustrates the critical component needed in any protection measure - robustness. Conversely, an increase in the level of strict protection in Białowieża and across the Europa 2000 network is a worthy goal as it would increase the robustness of the protection offered. Measures that are open to interpretation, and can be varied at the local level, are less likely to withstand attack by commercial interests. There is of course much value in a range of different levels of protection, and a certain amount of political pragmatism may be required in creating environmental legislation. However, legal unambiguity and prohibition of commercial considerations should be key components of both species- and habitat-based conservation measures.

Published online: 13 August 2018 https://doi.org/10.1038/s41559-018-0661-9

\footnotetext{
References

1. Bruskotter, J. T. et al. Conserv. Lett. https://doi.org/10.1111/ conl.12595 (2018).

2. Wilson, E. O. Half-Earth: Our Planet's Fight for Life (Liveright, New York, 2016).

3. Stokstad, E. Beetles are ravaging Europe's oldest forest. Is logging the answer? Science (5 December 2017).

4. Stokstad, E. Logging in Europe's primeval forest ruled illegal. Science (18 April 2018).
} 